University of Wollongong

Research Online

Australian Institute for Innovative Materials -

Papers

Australian Institute for Innovative Materials

$1-1-2020$

\title{
Na-doped ZnO UV filters with reduced photocatalytic activity for sunscreen applications
}

\author{
Rafid Abdlateef Mueen \\ University of Wollongong, ram627@uowmail.edu.au \\ Michael L. F Lerch \\ University of Wollongong, mlerch@uow.edu.au \\ Zhenxiang Cheng \\ University of Wollongong, cheng@uow.edu.au \\ Konstantin K. Konstantinov \\ University of Wollongong, konstan@uow.edu.au
}

Follow this and additional works at: https://ro.uow.edu.au/aiimpapers

Part of the Engineering Commons, and the Physical Sciences and Mathematics Commons 


\title{
Na-doped ZnO UV filters with reduced photocatalytic activity for sunscreen applications
}

\author{
Abstract \\ Due to its physical and chemical stability in addition to its transparency in the visible region with \\ ultraviolet protective activity, ZnO can be used in sunscreen applications. In our article, Na-doped zinc \\ oxide nanoparticles were prepared in different concentrations by sol-gel and solvothermal techniques to \\ reduce their photocatalytic activity. The photocatalytic activity of the doped samples was suppressed \\ effectively at a concentration of 0.03 at $\% \mathrm{Na}$ doping up to $90 \%$ by conducting the sol-gel process rather \\ than the solvothermal process which resulted in about $70 \%$ photocatalytic reduction in a period of time \\ from (0-30 $\mathrm{min}$ ) when exposed to ultraviolet and visible light. In addition, the nanoparticles resulted by \\ sol-gel route show a reduction in photoactivity under solar simulation about $98 \%$ rather than those \\ resulted via solvothermal process which shows a reduction around $92 \%$ for 30 min which is the same \\ period of time used for the photocatalytic degradation test. The particle size was around $64.6-84.6 \mathrm{~nm}$ \\ for samples prepared by both methods.

\section{Disciplines} \\ Engineering | Physical Sciences and Mathematics

\section{Publication Details} \\ Mueen, R., Lerch, M., Cheng, Z. \& Konstantinov, K. (2020). Na-doped ZnO UV filters with reduced \\ photocatalytic activity for sunscreen applications. Journal of Materials Science, 55 (7), 2772-2786.
}



sunscreen application

\author{
Rafid Mueen ${ }^{\mathrm{a}}$, Michael Lerch ${ }^{\mathrm{b}}$, Zhenxiang Cheng ${ }^{\mathrm{a}}$, and Konstantin \\ Konstantinov $^{\mathrm{a}^{*}}$ \\ ${ }^{a}$ Institute for Superconducting and Electronic Materials, Australian Institute for Innovative \\ Materials, University of Wollongong, Innovation Campus, Squires Way, North Wollongong, NSW \\ 2500, Australia \\ ${ }^{b}$ Centre for Medical and Radiation Physics, Faculty of Engineering and Information Science, \\ University of Wollongong, Northfields Avenue, Wollongong, NSW 2522, Australia \\ *Corresponding author: konstan@uow.edu.au
}




\begin{abstract}
Due to its physical and chemical stability in addition to its transparency in the visible region with ultraviolet protective activity, $\mathrm{ZnO}$ can be used in sunscreen applications. In our article, $\mathrm{Na}$ doped zinc oxide nanoparticles were prepared in different concentrations by sol-gel and Solvothermal techniques to reduce their photocatalytic activity. The photocatalytic activity of the doped samples was suppressed effectively at a concentration of 0.03 at\% Na doping up to $90 \%$ by conducting the sol-gel process rather than the Solvothermal process which resulted in about $70 \%$ photocatalytic reduction in a period of time from $(0-30 \mathrm{~min})$ when exposed to ultra violet and visible light. In addition the nanoparticles resulted by Sol-gel route shows a reduction in photoactivity under solar simulation about $98 \%$ rather than those resulted via Solvothermal process which shows a reduction around $92 \%$ for $30 \mathrm{~min}$ which is the same period of time used for the photocatalytic degradation test . The particle size was around 64.6- $84.6 \mathrm{~nm}$ for samples prepared by both methods.
\end{abstract}

Keywords: UV filters; ZnO; Photodegradation; sunscreens; ROS 


\section{Introduction}

In the past two decades, the concern for skin protection from ultraviolet (UV) radiation has attracted considerable attention due to the increased intensity of UV rays that can reach the Earth's surface as a result of the breakdown of the ozone layer[1, 2]. There are a number of reports on the risks from exposure to UV rays from sunlight[3, 4], such as skin aging[5-8], sunburn and sun-tanning phototoxicity, and skin cancer[1, 3, 9-12]. Most of them relate to the risks from the generation of reactive oxygen species (ROS), which are created during UV exposure. For this reason, the demand for efficient UV-protection has become very urgent [3, 12]. Most of the UV radiation that reaches the earth consists of UVA (around 95-99 \%) and UVB (around 1-5 \%) [11]. UVB is well known for its carcinogenic effects and causes erythema. Recently, UVA has also attracted attention, since, in comparison to UVB, it can penetrate deeply into the skin, which can result in significant health concerns $[4,6,8]$. Modern sunscreen products must diminish the radiation ranges of both UVA and UVB, since they both can cause health problems [13]. Therefore, the sunscreen agents represent one of the significant tools to protect the skin from UV irradiation. There are both organic and inorganic UV blockers in sunscreen products $[1,2,4,14-18]$. Because of the partial degradation of sunscreen organic filters by UV irradiation, which is suspected to increase UV-absorbent allergy and photoallergy, developing novel inorganic UV blockers that provide efficient UV protection over a wide spectrum, good comfort, and high safety when applied on the human skin is necessary [2, 19-21]. Inorganic materials can absorb, reflect, or scatter the ultraviolet radiation, depending on their particle size, unlike the organic blockers, which absorb the UV irradiation[1, 3, 8, 10,11, 13, 15, 22-25]. Nowadays, most inorganic UV-blocking filters are based on titanium dioxide $\left(\mathrm{TiO}_{2}\right)$ and zinc oxide $(\mathrm{ZnO})$ [1, 11, 13, 14, 24-26]. $\mathrm{ZnO}$ can provide protection in the UVA range, which is also dangerous solar radiation, since its harmful effects are not reflected in the current Sun Protection Factor (SPF) measurement technique, which is based on the erythema caused by UVB alone $[8,22,26]$. Indeed, $\mathrm{ZnO}$ is attractive for sunscreen formulization, and this relates to many advantages, such as its modest refractive index (2.0), its absorption of the small fraction of solar radiation in the UV range which is equal to or less than $385 \mathrm{~nm}$, its high probable recombination of photogenerated carriers (electrons and holes), large direct band gap, high exciton binding energy, non-risky nature, and high tendency towards chemical and physical stability. These advantages make the $\mathrm{ZnO}$ nanoparticles transparent in the visible region with UV protective activity, and therefore, the UV blocking ability of $\mathrm{ZnO}$ has been important [6, 15-17, 27, 28]. A significant issue for $\mathrm{ZnO}$ use in sunscreens is that it can generate ROS in the presence of UV light because of its photocatalytic 
activity. Therefore it is essential to make a non-photocatalytic $\mathrm{ZnO}$ material through doping with other metals[3, 15].

Several efforts have been made to deactivate the photocatalytic activity of $\mathrm{ZnO}$ by using inorganic surface modifiers. The doping of $\mathrm{ZnO}$ with different metals is another way to modify its photocatalytic activity [15, 29, 30]. Recently, successful doping of $\mathrm{ZnO}$ with different metals such as $\mathrm{Ce}, \mathrm{La}, \mathrm{Co}, \mathrm{Mn}, \mathrm{Al}, \mathrm{Li}, \mathrm{Na}, \mathrm{K}$, and $\mathrm{Cr}$ by various procedures, such as a simple and facile one-pot water bath, co-precipitation, and hydrothermal, Solvothermal, combustion, and sol gel methods has been reported. These materials exhibit greater performance than undoped $\mathrm{ZnO}$ towards decreasing the photocatalytic activity of $\mathrm{ZnO}$ in visible light. Therefore, metal doping can be an effective technique to modify the $\mathrm{ZnO}$ photocatalytic activity $[15,31$ 37]. In several papers, however, the photocatalytic activity of $\mathrm{ZnO}$ has been reduced successfully by doping with $\mathrm{Mn}, \mathrm{Ni}, \mathrm{N}$, and Co prepared by sol-gel, Solvothermal, and coprecipitation processes, respectively[30, 38-41]. These reports demonstrate that suitable doping and synthesis strategies have the potential to modify the photocatalytic properties of $\mathrm{ZnO}$ in the UVA range, and they can be used to create $\mathrm{ZnO}$ UV filters with reduced photocatalytic activity. In the current article, we report reduction of the UV photocatalytic activity of $\mathrm{Na}$ doped $\mathrm{ZnO}$ fabricated through sol-gel and hydrothermal methods.

\section{Experimental section}

\subsection{Chemicals}

Zinc acetate dehydrate, $\mathrm{Zn}\left(\mathrm{CH}_{3} \mathrm{COO}\right)_{2} \cdot 2 \mathrm{H}_{2} \mathrm{O}, 99.999 \%$ used as the source of $\mathrm{Zn}$, sodium nitrate, $\mathrm{NaNO}_{3}$, purity $\geq 99.0 \%$ as the source of $\mathrm{Na}$, commercial $\mathrm{ZnO}$ nanopowder, ethanol amine $\left(\mathrm{C}_{2} \mathrm{H}_{7} \mathrm{NO}\right.$, purity $\left.\geq 99.5 \%\right)$, and methanol, were purchased from SIGMA ALDRICH and used to synthesize $\mathrm{Na}$ doped $\mathrm{ZnO}$.

\subsection{Sample preparation}

We have emphasized cost-effective methods that can be scaled up for industrial application. In this report, commercial $\mathrm{ZnO}$ nanoparticles and $\mathrm{Na}$ doped $\mathrm{ZnO}$ nanoparticles produced by solgel and Solvothermal methods were used.

\subsubsection{Sol-gel method}

Firstly, $0.25 \mathrm{M}$ of each starting material was prepared, and then they were separately stirred and dissolved in ethanolamine (10.975 $\mathrm{g}$ of zinc acetate dehydrate in $200 \mathrm{ml}$ of ethanolamine and $0.424 \mathrm{~g}$ of $\mathrm{NaNO}_{3}$ in $20 \mathrm{ml}$ of ethanolamine). Secondly, specific quantities of the two resulting solutions were mixed in a beaker, so as to achieve $\mathrm{Na}$ doping levels of 0.03 and 0.05 at $\%$, and stirred using a magnetic stirrer at temperatures ranging from $60-80^{\circ} \mathrm{C}$ for $120-190$ 
min. Finally, the gelatine product obtained was calcined for two hours at $500^{\circ}$, and then the samples were ground for characterisation.

\subsubsection{Solvothermal method}

Initially, $0.25 \mathrm{M}$ each of the prepared materials was separately stirred and dissolved in methanol, whereas the same amounts of zinc acetate dehydrate and sodium nitrate as listed above were also used for the preparation in $200 \mathrm{ml}$ and $20 \mathrm{ml}$ of ethanol, respectively, and the same doping levels were used. Then, the Solvothermal process was conducted thermally in a stainless steel vessel in a vacuum drying oven (VDO-30 $\mathrm{CH}$ ), and the samples were held at $150^{\circ}$ overnight and cooled down to room temperature. Finally, the milky solution was centrifuged and washed three times with water and ethanol, then dried at $80^{\circ}$ overnight and ground into powder for characterisation. Table 1 shows the preparation conditions for the resultant samples produced by the sol-gel and Solvothermal approaches.

Table 1 Preparation conditions for samples produced by the sol-gel and Solvothermal methods.

\begin{tabular}{lcccccc}
\hline Method & $\begin{array}{c}\text { Sample } \\
\text { Label }\end{array}$ & $\begin{array}{c}\mathrm{Zn} \\
\text { (at \%) }\end{array}$ & $\begin{array}{c}\mathrm{Na} \\
(\text { at \% })\end{array}$ & $\begin{array}{c}\text { Oven } \\
\text { temperature } \\
\left(\mathrm{C}^{\circ}\right)\end{array}$ & $\begin{array}{c}\text { Annealing } \\
\text { temperature } \\
\left({ }^{\circ} \mathrm{C}\right)\end{array}$ & $\begin{array}{c}\text { Annealing } \\
\text { time }(\mathrm{h})\end{array}$ \\
\hline Sol-gel & $\mathrm{Sg} 1$ & 9.97 & 0.03 & - & 500 & 2 \\
Sol-gel & $\mathrm{Sg} 2$ & 9.95 & 0.05 & - & 500 & 2 \\
Solvothermal & $\mathrm{Sv1}$ & 9.97 & 0.03 & 180 & 500 & 2 \\
Solvothermal & $\mathrm{Sv} 2$ & 9.95 & 0.05 & 180 & 500 & 2 \\
\hline
\end{tabular}

\subsection{Characterisation}

The purity and crystallinity of the as-prepared samples were characterized by X-ray diffraction (XRD, GBC, MMA) at room temperature. The X-ray diffraction (XRD) measurements on powder samples were performed on an XPERT-PRO 9 9PW 3050/60 equipped with $\mathrm{Cu} \mathrm{K} \alpha$ radiation $(\lambda=1.54060 \AA)$ operated at $40 \mathrm{kV}$ and $30 \mathrm{~mA}$. Samples were scanned within the angular range of 20- 80 degrees with a scanning rate of 0.2 degree / min. Morphologies of the synthesized samples were characterized with a scanning electron microscope (SEM, JEOL JSM-7500FA) and a transmission electron microscope (TEM, JOEL ARM-200F).The photocatalytic properties of the samples were tested in a Rayonet Photochemical Chamber Reactor (RPR) providing radiation in the UVB + UVA range using crystal violet dye. Simulated sun irradiation of the synthesized samples was conducted in a LCS - $100^{\mathrm{TM}}$ solar simulator. The UV absorption and dye photodegradation were tested in a Shimadzu UV-3600. Diffuse reflectance spectroscopy was used to calculate the band gaps of the pure and prepared 
samples. X-ray photoelectron spectroscopy (XPS) was conducted using a SPECS PHOIBOS 100 Analyser installed in a high-vacuum chamber with the base pressure below 10-8 mbar. XPS was used to analyse the valence state of $\mathrm{Zn}$ and provide information on the surface chemical composition of the materials. X-ray excitation was provided by $\mathrm{Al} \mathrm{K} \alpha$ radiation with photon energy, $h v=1486.6 \mathrm{eV}$ at the high voltage of $12 \mathrm{kV}$ and power of $120 \mathrm{~W}$. The XPS binding energy spectra were recorded at the pass energy of $20 \mathrm{eV}$ in the fixed analyser transmission mode. Analysis of the XPS data was carried out using the commercial CasaXPS 2.3.15 software package.

\subsection{Photocatalytic and sun simulator tests}

The pure $\mathrm{ZnO}$ and $\mathrm{Na}$ doped $\mathrm{ZnO}$ were used as photocatalysts and crystal violet as an evaluating agent. The test was carried out as follows: $5 \mathrm{mg}$ of pure and $\mathrm{Na}$ doped $\mathrm{ZnO}$ was dispersed and magnetically stirred in $100 \mathrm{ml}$ of crystal violet, respectively, for $30 \mathrm{~min}$ in the dark. Next, the prepared suspensions were irradiated in an RPR reactor under an Hg lamp with wavelengths fixed at $300 \mathrm{~nm}$ and $350 \mathrm{~nm}$, and located $20 \mathrm{~cm}$ away from the $150 \mathrm{ml}$ beaker. Different time periods of exposure were recorded from 0-30 min, with an aliquot taken each five min. Finally, the UV-visible (UV vis) spectra of the irradiated suspensions were collected on a UV-3600 Shimadzu. The same method was carried out for the sun simulator, but the final suspension was irradiated by an LCS - $100^{\mathrm{TM}}$ solar simulator with 1 sun solar irradiation.

\section{Results and discussion}

\subsection{X-ray diffraction (XRD)}

The XRD analysis shows that all the as-prepared $\mathrm{ZnO}$ samples have a polycrystalline structure and very good crystallinity. Figure 1 and 2 presents the XRD spectra of the undoped and Nadoped $\mathrm{ZnO}$ nanoparticles synthesized by the sol-gel and Solvothermal methods respectively. All peaks can be well indexed to hexagonal wurtzite $\mathrm{ZnO}$ [(space group P6 3 mc or (186)/amd, JCPDS No. 96-230-0114] zinc oxide, indicating high purity and good crystallinity. It can be observed in the figure that the samples are polycrystalline in nature, possessing the hexagonal wurtzite structure. It is also observed that there is no impurity phase corresponding to Na. The most intensive diffraction peaks of zincite, the (100) and (101) peaks, were selected to calculate the cell parameters. Tables 2 and 3 show the cell parameters, average crystallite size, $d$-spacing, amount of $\mathrm{Na}$, identifications of peaks, and the corresponding phase angles. 


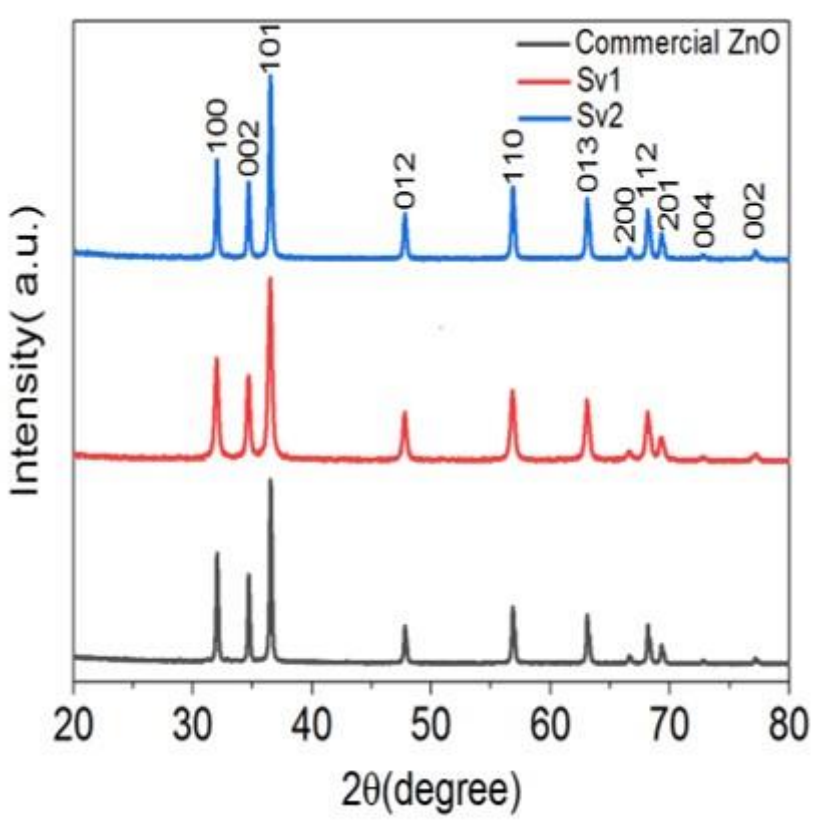

Fig 2 XRD patterns of commercial and Na-doped ZnO nanoparticles of Sv1- 0.03 and Sv20.05 prepared via Solvothermal method. 
Table 2 Cell parameters, average crystallite size, d-spacing, amount of $\mathrm{Na}$, and peaks and their phase angles for samples grown by the sol-gel process.

\begin{tabular}{llllllll}
\hline $\begin{array}{l}\mathrm{Na} \\
(\mathrm{at} \%)\end{array}$ & Sample & Peak & $\begin{array}{l}d \text {-spacing } \\
(\mathrm{nm})\end{array}$ & $\theta\left(^{\circ}\right)$ & $a(\AA)$ & $c(\AA)$ & $\begin{array}{l}\text { Crystallite } \\
\text { size }(\mathrm{nm})\end{array}$ \\
\hline 0 & $\begin{array}{l}\text { Commercial } \\
\mathrm{ZnO}\end{array}$ & 100 & 2.777 & 32.20 & 3.207 & 5.18 & 98.8 \\
& 101 & 2.448 & 36.68 & & 4 & \\
0.03 & $\mathrm{Sg} 1$ & 100 & 2.8014 & 31.92 & 3.235 & 5.19 & 86.6 \\
& & 101 & 2.4650 & 36.42 & & 1 & \\
0.05 & $\mathrm{Sg} 2$ & 100 & 2.8143 & 31.77 & 3.253 & 5.19 & 72.6 \\
& & 101 & 2.4748 & 36.27 & & 8 & \\
\hline
\end{tabular}

Table 3 Cell parameters, average crystallite size, d-spacing, amount of $\mathrm{Na}$, and peaks and their phase angles for the solvothermal process.

\begin{tabular}{llllllll}
\hline $\begin{array}{l}\mathrm{Na} \\
\text { (at\%) }\end{array}$ & Sample & Peak & $\begin{array}{l}d \text {-spacing } \\
(\mathrm{nm})\end{array}$ & $\theta\left(^{\circ}\right)$ & $a(\AA)$ & $c(\AA)$ & $\begin{array}{l}\text { Crystallite } \\
\text { size }(\mathrm{nm})\end{array}$ \\
\hline & $\begin{array}{l}\text { Commercial } \\
0\end{array}$ & 100 & 2.777 & 32.20 & 3.207 & 5.184 & 98.8 \\
& ZnO & 101 & 2.448 & 36.68 & & & \\
0.03 & Sv1 & 100 & 2.7946 & 31.95 & 3.227 & 5.191 & 64.6 \\
& & 101 & 2.4610 & 36.48 & & & \\
0.05 & Sv2 & 100 & 2.8117 & 31.80 & 3.253 & 5.198 & 34.7 \\
& & 101 & 2.4722 & 36.31 & & & \\
\hline
\end{tabular}

\subsection{Morphologies}

Figures (3-7) show SEM, TEM, and high resolution TEM (HRTEM) images, with the corresponding selected area electron diffraction (SAED) patterns of the commercial and Nadoped commercial $\mathrm{ZnO}$ nanoparticles. The samples resulted from Sol-gel routed noted by A nearly spherical type of nanoparticle morphology was observed, and the particle sizes were, on average, less than for the commercial $\mathrm{ZnO}$ (Tables 2 and 3). Figuthey also show images of nanoparticles obtained by both the sol-gel and the solvothermal methods, which clearly demonstrate that both types of nanoparticles possess nearly spherical morphology. Both $a$ and $c$ lattice parameters were clearly increased, which led to an increase in unit cell volume for the as-prepared samples synthesised by both methods. The platelet particles of pure $\mathrm{ZnO}$ mostly vanished when doped with $\mathrm{Na}$ in different amounts, and their particle size was greatly reduced, ranging between 72.6-86.6 nm for the nanocrystals produced by sol-gel approach and 34.7$64.6 \mathrm{~nm}$ for the nanoparticles resulting from the solvothermal process. For more details of the pure and doped $\mathrm{ZnO}$, TEM images and SAED patterns were collected, and they indicated very 
good crystallinity for the as-prepared samples, as clearly shown in the lattice fringes, which are also consistent with the XRD patterns. The lattice spacings of the pure $\mathrm{ZnO}$ and prepared samples are $0.2447,02470,0.2603,0.2467$, and $0.2807 \mathrm{~nm}$, which correspond to the (101), (101), (002), (101), and (100) planes for the pure $\mathrm{ZnO}, \mathrm{Sg} 1, \mathrm{Sg} 2$, Sv1, and Sv2 samples, respectively.

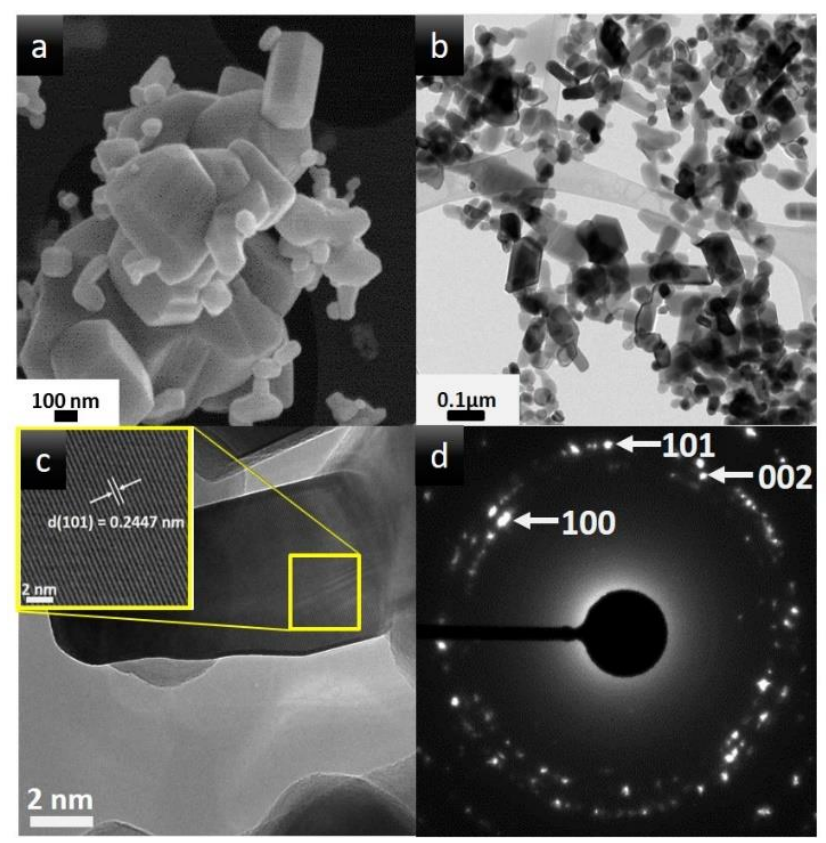

Fig 3 SEM, TEM, and HRTEM images, and SAED patterns for Commercial ZnO.

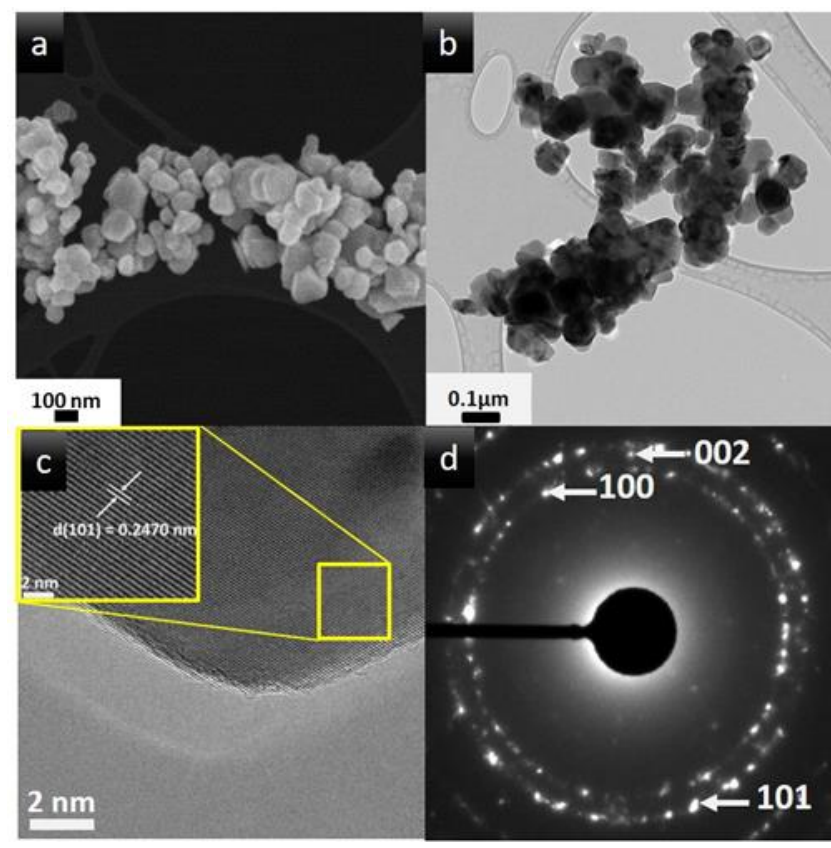

Fig 4 SEM, TEM, and HRTEM images, and SAED patterns for Sg1 from the Sol-gel process- 0.03 doping. 


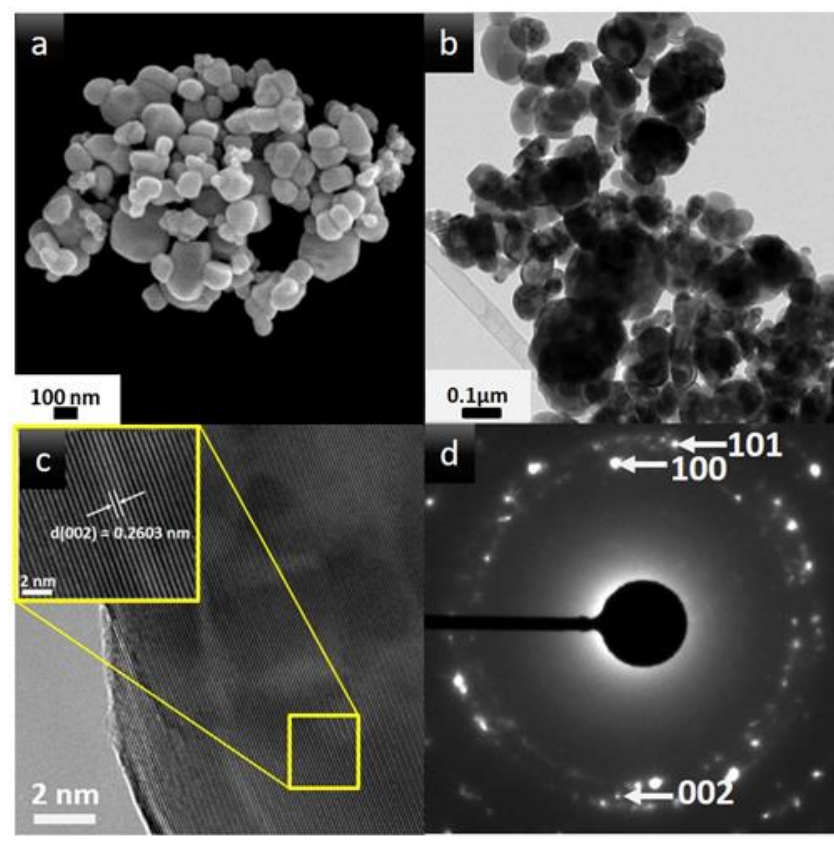

Fig 5 SEM, TEM, and HRTEM images, and SAED patterns for Sg2 from the Sol-gel process- 0.05 doping.

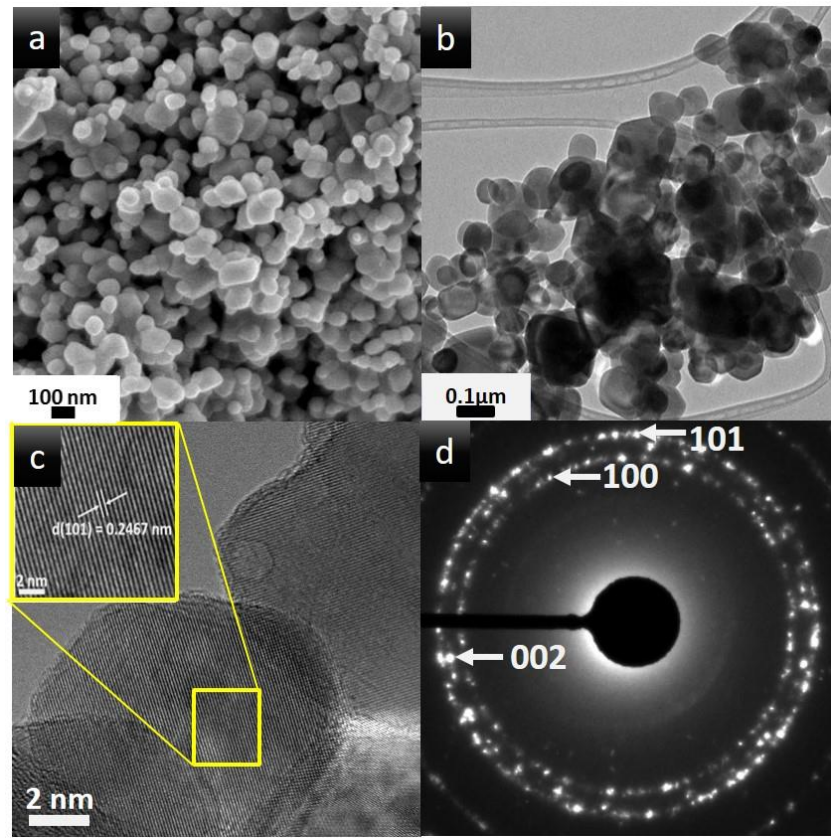

Fig 6 SEM, TEM, and HRTEM images, and SAED patterns for Sv1 from the Solvothermal process- 0.03 doping. 


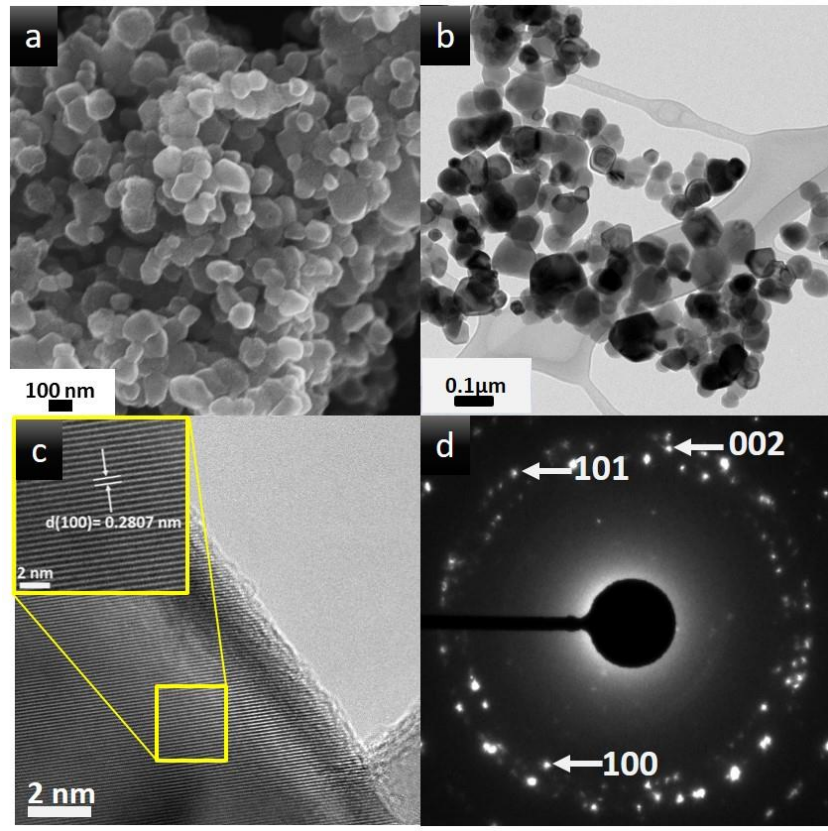

Fig 7 SEM, TEM, and HRTEM images, and SAED patterns for Sv2 from the Solvothermal process- 0.05 doping.

\subsection{UV-visible spectroscopy}

UV-visible spectra of the prepared samples are shown in Figures 8 and 9 which were recorded in the range of $200-800 \mathrm{~nm}$ for optical band-gap calculations. Samples of $\mathrm{Na}$ doped $\mathrm{ZnO}$, $\mathrm{Sg} 1$ from the sol-gel method and Sv1 from the Solvothermal method, showed less absorption compared to undoped commercial $\mathrm{ZnO}$, but they exhibited less degradation compared with commercial $\mathrm{ZnO}$ regarding the dye, especially $\mathrm{Sg} 1$, which a showed lack of photocatalytic activity towards the dye. 


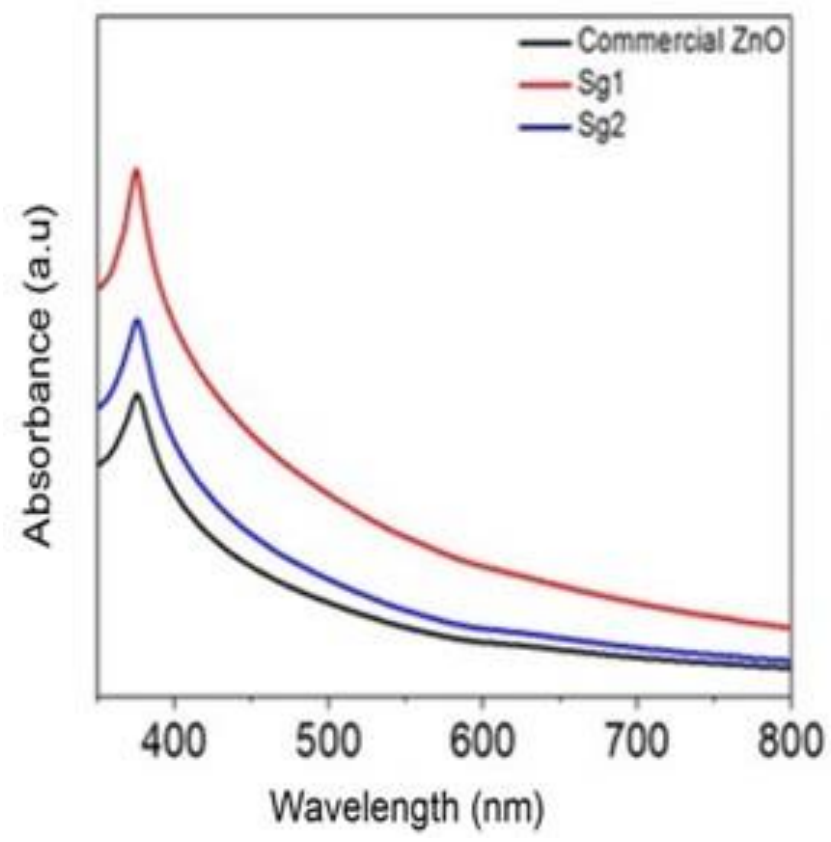

Fig 8 UV-visible spectra of the commercial and Na-doped ZnO nanoparticle of Sg1-0.03, Sg2- 0.05 samples prepared by the sol-gel method.

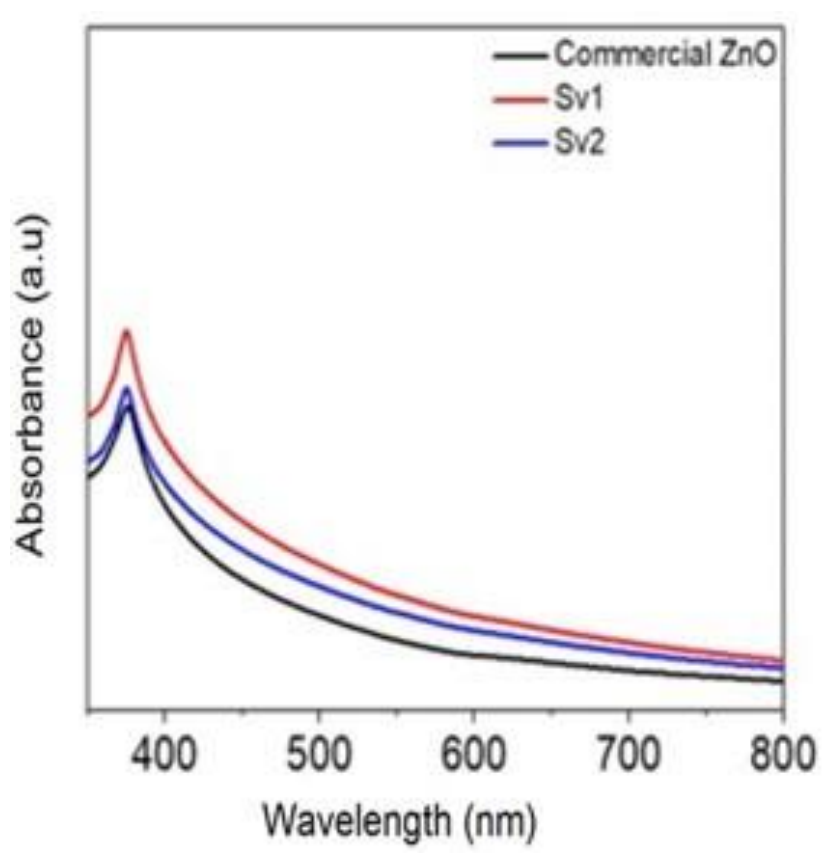

Fig 9 UV-visible spectra of the commercial and Na-doped ZnO of Sv1-0.03, Sv2- 0.05 prepared by the Solvothermal method.

\subsection{Band gap measurements}

By using diffuse reflectance spectroscopy to investigate the pure commercial $\mathrm{ZnO}$ and the doped samples (Sg1, Sg2, Sv1, Sv2) that resulted from the sol-gel and Solvothermal methods, respectively, the band gaps for the samples have been calculated by plotting $(\alpha h v)^{2}$ versus $h v$ 
in $(\mathrm{eV})$, where $\alpha$ is the absorption coefficient, $h$ is Planck's constant, and $v$ is the frequency, as shown in Figures 10 and 11. The extrapolation of the linear portion of the curve to $\alpha=0$ gives the band-gap value $\left(E_{\mathrm{g}}\right)$, as shown in Table 3. The data show that doping with Na has shifted the band gap of $\mathrm{ZnO}$ to UVA. Note that the samples prepared by the sol-gel route show higher shifting towards UVA, up to $387.5 \mathrm{~nm}$, compared to those prepared by the Solvothermal method, which reached $381.53 \mathrm{~nm}$, as illustrated in Table 4.

Table 4 Band-gap energy (Eg) for photocatalysis of the commercial and Na-doped $\mathrm{ZnO}$ nanoparticle samples of Sg1- 0.03, Sg2- 0.05 prepared by the sol-gel route and Sv1-0.03 Sv20.05 prepared by Solvothermal method.

\begin{tabular}{lcl}
\hline Samples & $\mathrm{E}_{\mathrm{g}}(\mathrm{eV})$ & $\lambda(\mathrm{nm})$ \\
\hline Commercial & 3.33 & 372.37 \\
$\mathrm{ZnO}$ & & \\
$\mathrm{Sg} 1$ & 3.20 & 387.5 \\
$\mathrm{Sg} 2$ & 3.25 & 381.53 \\
$\mathrm{~Sv} 1$ & 3.25 & 381.53 \\
$\mathrm{~Sv} 2$ & 3.29 & 376.89 \\
\hline
\end{tabular}

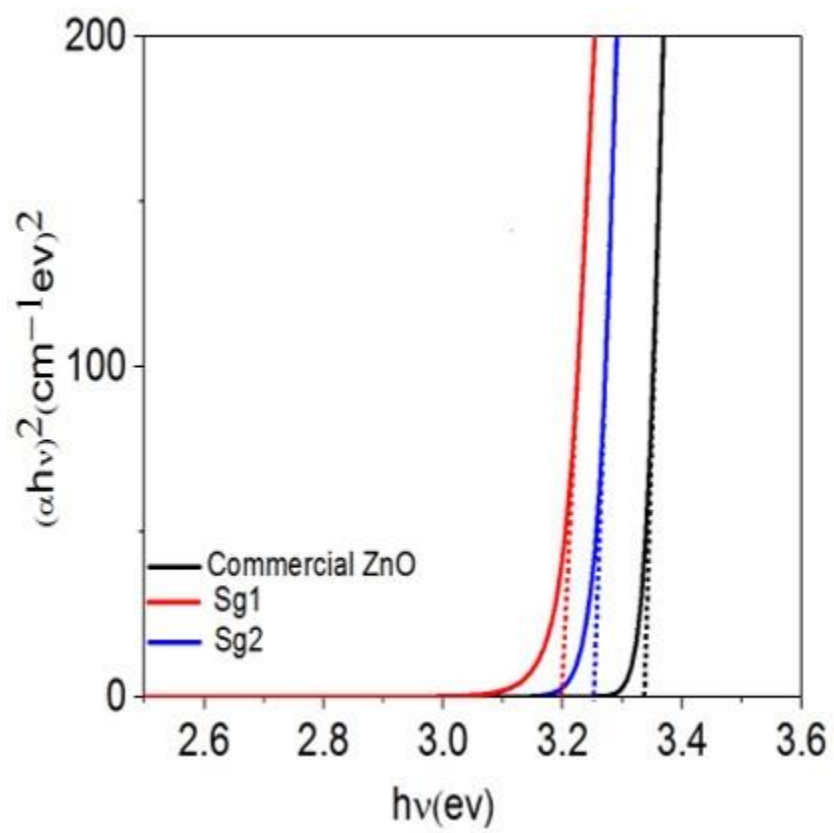

Fig 10 Plot of $(\alpha h v)^{2}$ as a function of energy $(h v)$ for commercial and Na-doped $\mathrm{ZnO}$ nanoparticle of Sg1- 0.03, Sg2- 0.05 samples prepared by the sol-gel method and (Sv1- 0.03, Sv2- 0.05) prepared by the Solvothermal method. 


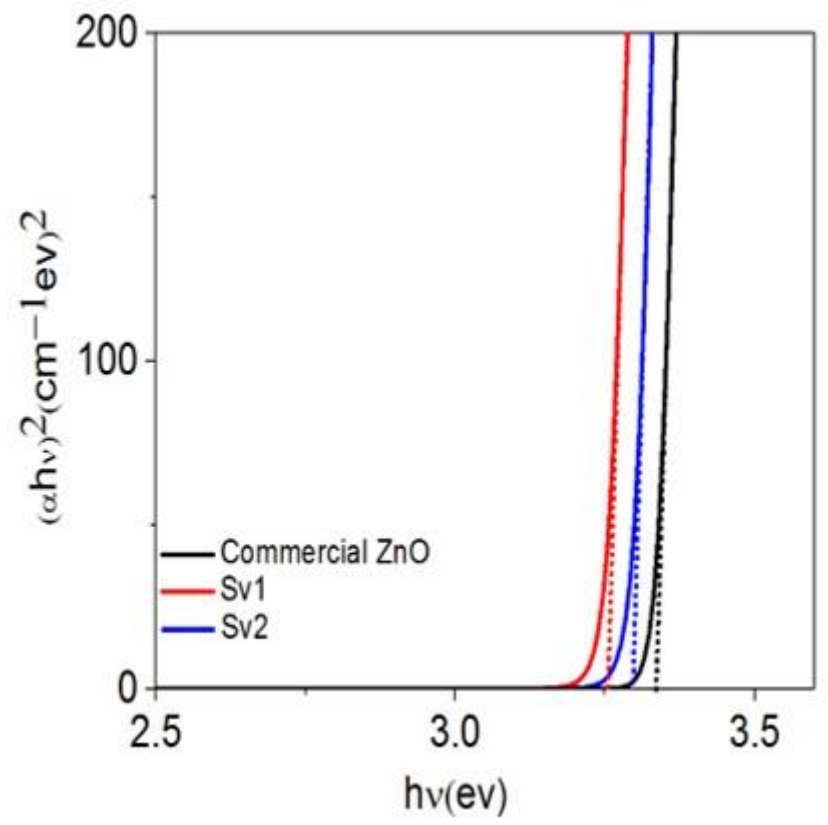

Fig 11 Plot of ( $\alpha \mathrm{hv}) 2$ as a function of energy (hv) for commercial and $\mathrm{Na}$-doped $\mathrm{ZnO}$ nanoparticle of Sv1- 0.03, Sv2- 0.05 prepared by the Solvothermal method.

\subsection{Photocatalytic activity}

The photocatalytic activity of the synthesized materials was recorded for time periods from 0 to 30 min on a Rayonet Photochemical Chamber Reactor (RPR), operating from 120-277 V, 50-60 Hz. Figures 12 and 13 show their degradation properties compared to commercial $\mathrm{ZnO}$. 


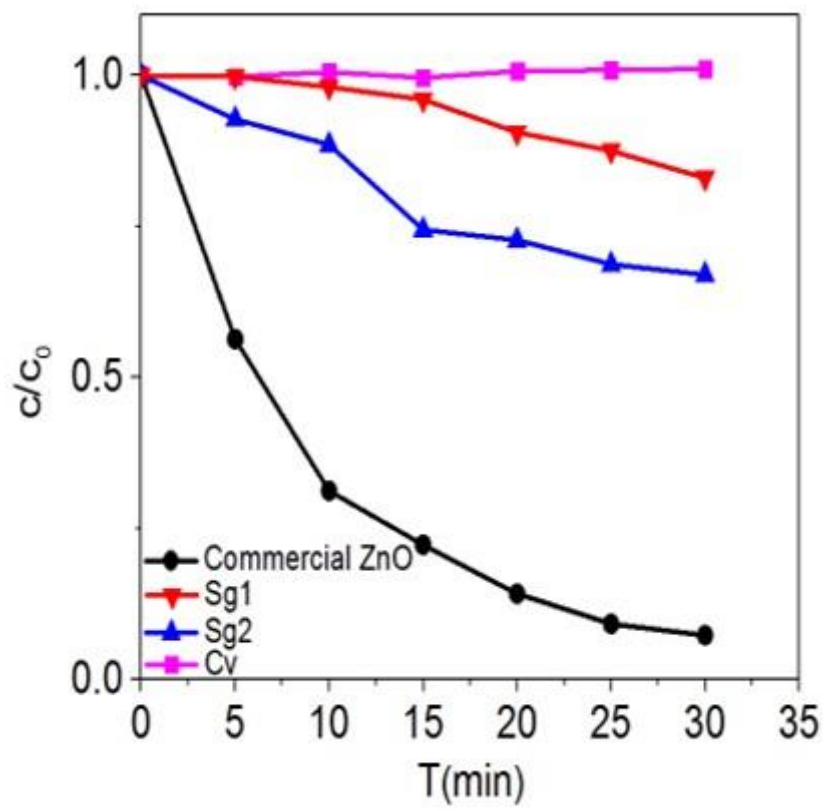

Fig 12 Photocatalytic activity towards crystal violet dye (CV) of commercial and Na-doped $\mathrm{ZnO}$ nanoparticles in terms of relative dye degradation over time for the samples Sg1- 0.03, Sg2- 0.05 synthesised via sol-gel proccess.

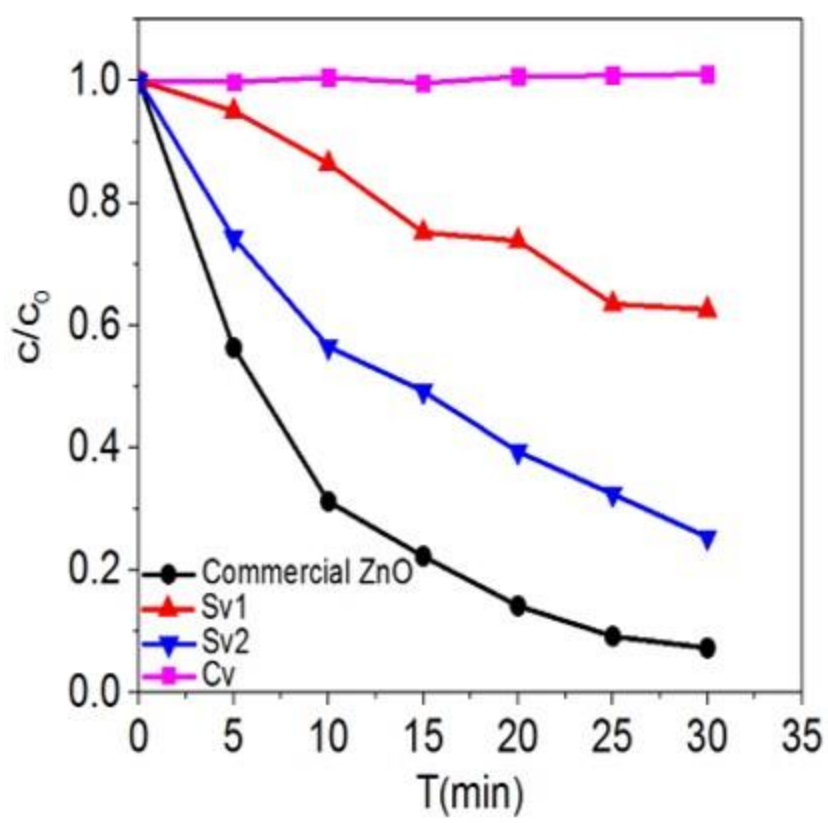

Fig 13 Photocatalytic activity towards crystal violet dye (CV) of commercial and Na-doped $\mathrm{ZnO}$ nanoparticles in terms of relative dye degradation over time of the samples Sv1- 0.03, Sv2- 0.05 synthesised by Solvothermal process.

From the above, we can see that the samples fabricated by the sol-gel process clearly show higher performance towards suppression of the degradation compared to the Solvothermal route. This may be due to the effects of the synthesis conditions, which create surface oxygen 
vacancies during the decomposition of organic species containing carbon at high temperature, because such conditions do not exist in the Solvothermal synthesis. Therefore, the sol-gel method is more suitable for UV sunscreen applications than the Solvothermal.

\subsection{Solar simulation}

Figures 14 and 15 show the solar simulation properties of our samples compared to commercial $\mathrm{ZnO}$. The solar simulation properties of the synthesized nanoparticles were recorded from 0 to 30 min using an LCS $-100^{\mathrm{TM}}$ solar simulator with simulated 1 sun solar irradiation.

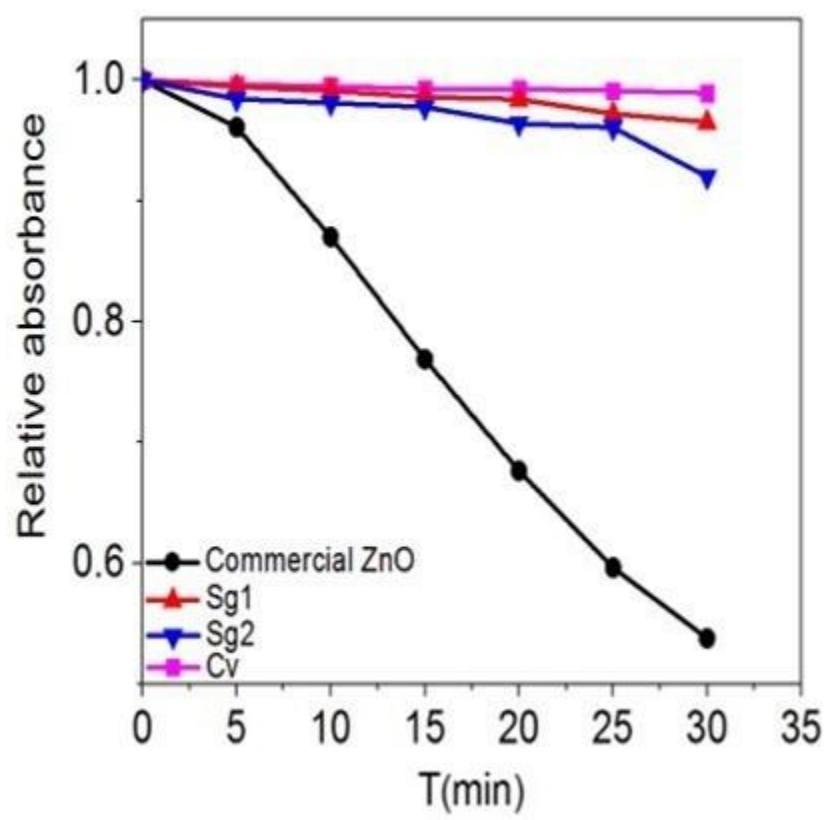

Fig 14 Degradation of crystal violet dye (CV) over time with exposure to simulated 1 sun solar irradiation in conjunction with commercial and $\mathrm{Na}$-doped $\mathrm{ZnO}$ nanoparticles of $\mathrm{Sg} 1$ 0.03, Sg2- 0.05 produced by the sol-gel Solvothermal (Sv1-0.03, Sv2- 0.05) method. 


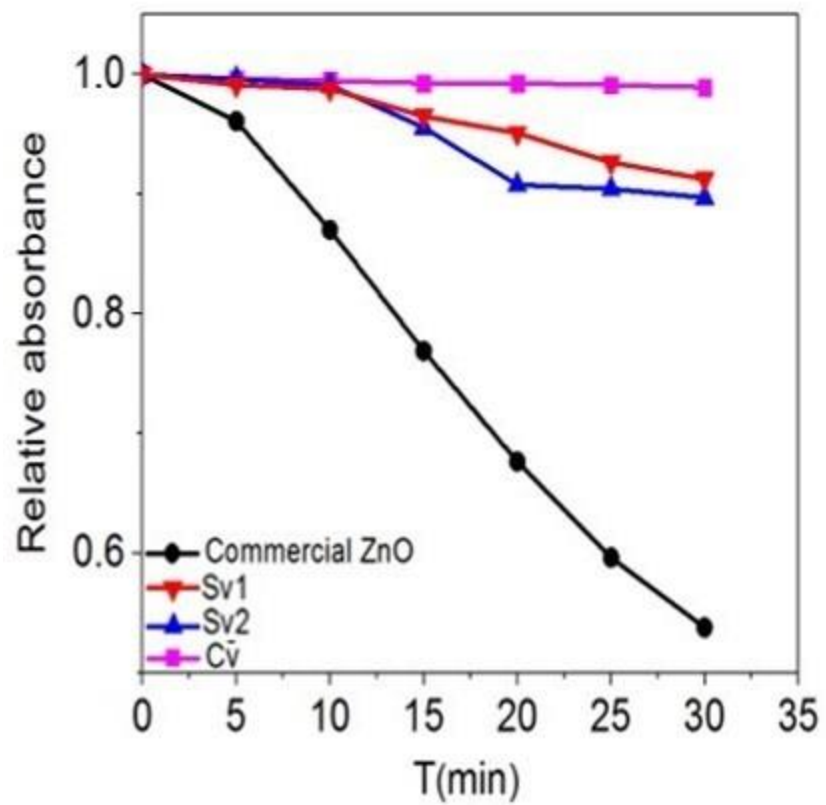

Fig 15 Degradation of crystal violet dye (CV) over time with exposure to simulated 1 sun solar irradiation in conjunction with commercial and Na-doped $\mathrm{ZnO}$ nanoparticles of Sv1-0.03, Sv2- 0.05 produced by the Solvothermal method.

\subsection{X-ray photoelectron spectroscopy (XPS)}

Typical XPS survey spectra of the undoped and Na-doped $\mathrm{ZnO}$ nanoparticles can be seen in Figures 16 and 17. High resolution scans for $\mathrm{C}, \mathrm{O}, \mathrm{Zn}$, and Na were also performed. The survey spectra demonstrate that the main peaks correspond to $\mathrm{Zn} 2 \mathrm{p}_{1 / 2}$ and $2 \mathrm{p}_{3 / 2}, \mathrm{O} 1 \mathrm{~s}, \mathrm{Na} 1 \mathrm{~s}$, and $\mathrm{C}$ 1s orbitals for the pure $\mathrm{ZnO}$ and the prepared samples synthesized by both the sol-gel ( $\mathrm{Sg} 1$, $\mathrm{Sg} 2)$ and Solvothermal (Sv1, Sv2) methods.

According to the XPS curves and typical studies the $\mathrm{Zn}$ and $\mathrm{O}$ peaks were prominent, and the curves of the prepared samples ( $\mathrm{Sg} 1, \mathrm{Sg} 2, \mathrm{~Sv} 1$, and $\mathrm{Sv} 2$ ) show that the doping process was successfully done, although the peaks that are related to $\mathrm{Na}$ are very weak. Generally, the peaks at 1022.79 and $1045.86 \mathrm{eV}$ are respectively related to the core lines of the $\mathrm{Zn} 2 \mathrm{p}_{3 / 2}$ and $2 \mathrm{p}_{1 / 2}$ states. The difference in binding energy between the two peaks was around $23.07 \mathrm{eV}$, which is consistent with the standard reference values for $\mathrm{ZnO}$. The predictable values of the binding energies and the difference in binding energy in the $\mathrm{Zn} 2 \mathrm{p}$ spectrum show that $\mathrm{Zn}$ is in the +2 oxidation state. The core level O 1s peaks for Na-doped $\mathrm{ZnO}$, centred at 531.30 and $533.15 \mathrm{eV}$, might be shaped in two ways: firstly, from the oxygen of $\mathrm{ZnO}$, and secondly, from partial $\mathrm{Na}-$ $\mathrm{O}-\mathrm{Na}$ bonding. The low binding energy peak $(531.30 \mathrm{eV})$ can be referred to the $\mathrm{O}-\mathrm{Zn}$ bond, which is related to the O-2 ions in the wurtzite structure of the hexagonal $\mathrm{Zn}^{2+}$ ion group. Furthermore, the higher energy peak $(533.15 \mathrm{eV})$ is commonly attributed to the presence of the 
$\mathrm{Zn}(\mathrm{OH})_{2}$ phase, so that the formation of this peak may be attributed to the absorption of atmospheric moisture. $\mathrm{Na}$ and $\mathrm{C}$ peaks were observed for $\mathrm{Na} 1 \mathrm{~s}(1071.39 \mathrm{eV})$ and $\mathrm{C} 1 \mathrm{~s}(287.92$ $\mathrm{eV}$ ). The positions of $\mathrm{C}, \mathrm{O}$, and $\mathrm{Zn}$ peaks in $\mathrm{Sg} 1, \mathrm{Sg} 2, \mathrm{~Sv} 1$, and $\mathrm{Sv} 2$ are the same as for the reference commercial $\mathrm{ZnO}$. All of the measurements related to $\mathrm{Zn} 2 \mathrm{p}, \mathrm{Na} 1 \mathrm{~s}$, and $\mathrm{O}$ 1s represent the perfect samples (Sg1 and Sv1) for each synthesis (sol-gel and Solvothermal) method, and the other samples Sg2 and Sv2 are included as well for comparison.
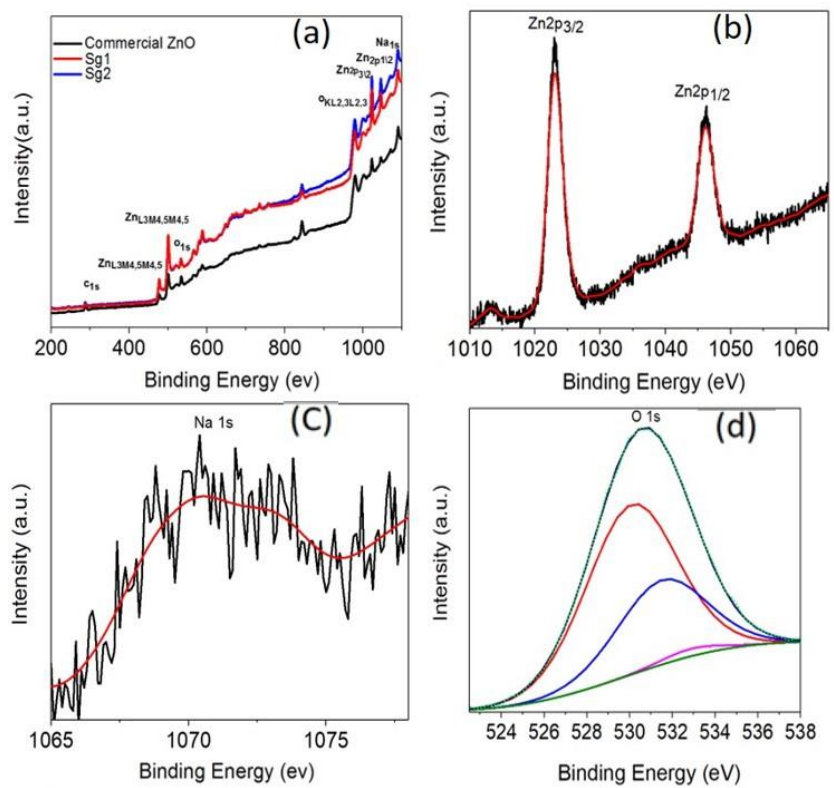

Fig 16 Typical XPS (a) survey spectra and higher resolution (b) Zn 2p, (c) Na 1s, and (d) C 1s peaks for the commercial and Na-doped ZnO nanoparticles of Sg1-0.03, Sg2-0.05 synthesized by the sol-gel method. 

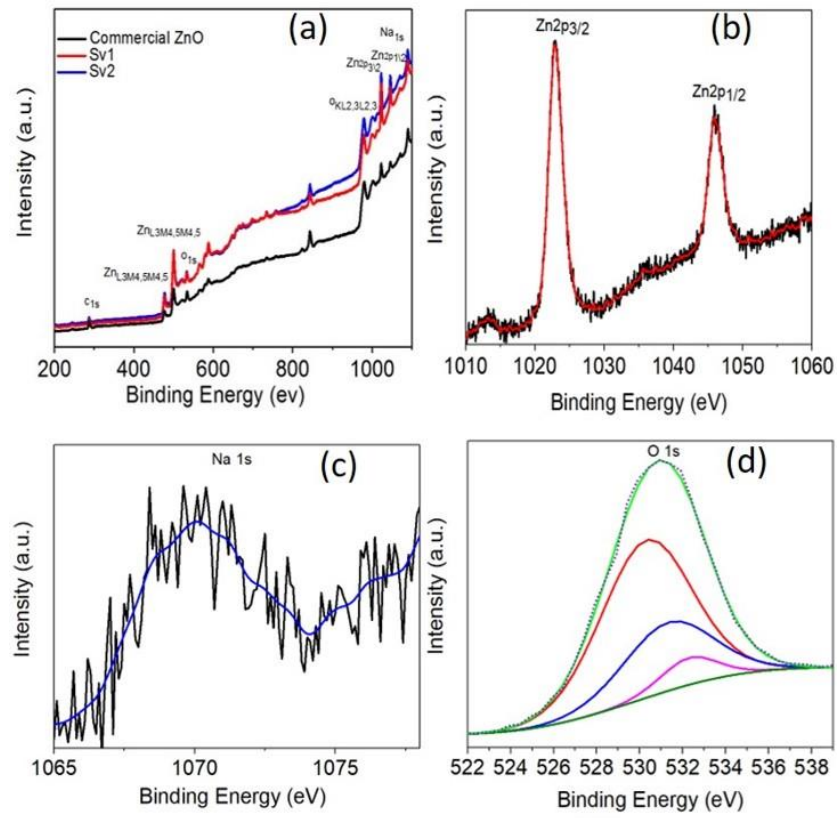

Fig 17 Typical XPS (a) survey spectra and higher resolution (b) Zn 2p, (c) Na 1s, and (d) C 1s peaks for the commercial and Na-doped ZnO nanoparticles of Sv1-0.03, Sv2-0.05 synthesized by the Solvothermal method.

\section{Conclusions}

In conclusion, we employed cost effective nanotechnologies to fabricate sodium-doped zinc oxide nanoparticles with super-low photoactivity that would be suitable for UVA filters in sunscreens. Zinc acetate dehydrate was doped by sodium in different doping concentrations using the sol-gel and Solvothermal routes. The experimental results show an increase in the cell parameters and decreased particle size as a function of doping concentration. These modifications may lead to a significant modification in the photocatalytic activity of $\mathrm{ZnO}$ towards deactivation under UV and visible light, especially at the doping level of 0.03 at $\%$ for the samples prepared by the sol-gel which was around 90\% rather than the Solvothermal method that shows deactivation about $70 \%$ for $30 \mathrm{~min}$. In addition, the photoactivity of the $\mathrm{ZnO}$ has been reduced up to $98 \%$ for samples resulted by Sol-gel method and $92 \%$ for those resulted via Solvothermal route under solar simulation also in $30 \mathrm{~min}$. Furthermore, at the same doping level, the band gap was increased to reach the UVA region. 


\section{References}

1. El-Toni, A.M., S. Yin, T. Sato, T. Ghannam, M. Al-Hoshan, and M. Al-Salhi, Investigation of photocatalytic activity and UV-shielding properties for silica coated titania nanoparticles by solvothermal coating. Journal of Alloys and Compounds, 2010. 508(1): p. L1-L4.

2. Furusawa, T., K. Honda, E. Ukaji, M. Sato, and N. Suzuki, The microwave effect on the properties of silica-coated TiO2 fine particles prepared using sol-gel method. Materials Research Bulletin, 2008. 43(4): p. 946-957.

3. Liu, X., S. Yin, and T. Sato, Synthesis of broad-spectrum UV-shielding plate-like titanate/calciadoped ceria composite in different $\mathrm{pH}$ solution. Materials Chemistry and Physics, 2009. 116(23): p. 421-425.

4. Kullavanijaya, P. and H.W. Lim, Photoprotection. Journal of the American Academy of Dermatology, 2005. 52(6): p. 937-958.

5. Shafei, A.E. and A. Abou-Okeil, ZnO/carboxymethyl chitosan bionano-composite to impart antibacterial and UV protection for cotton fabric. Carbohydrate Polymers, 2011. 83(2): p. 920925.

6. Im, Y.M., T.H. Oh, J.A. Nathanael, and S.S. Jang, Effect of ZnO nanoparticles morphology on UV blocking of poly(vinyl alcohol)/ZnO composite nanofibers. Materials Letters, 2015. 147: p. 2024.

7. Lee, s., UV Protective Properties of Nonwoven Fabrics for Clothing and Analysis of the Influential Factors. J Korean Soc Living Environ Syst, 2009. 16(2): p. 134-142.

8. Pinnell, S.R., D. Fairhurst, R. Gillies, M.A. Mitchnick, and N. Kollias, Microfine Zinc Oxide is a Superior Sunscreen Ingredient to Microfine Titanium Dioxide. Dermatologic Surgery, 2000. 26(4): p. 309-314.

9. Scharffetter-Kochanek, K., M. Wlaschek, P. Brenneisen, M. Schauen, R. Blaudschun, and J. Wenk, UV-induced reactive oxygen species in photocarcinogenesis and photoaging. Biological chemistry, 1997. 378(11): p. 1247-1258.

10. Herzog, B., S. Mongiat, C. Deshayes, M. Neuhaus, K. Sommer, and A. Mantler, In vivo and in vitro assessment of UVA protection by sunscreen formulations containing either butyl methoxy dibenzoyl methane, methylene bis-benzotriazolyl tetramethylbutylphenol, or microfine ZnO. International Journal of Cosmetic Science, 2002. 24(3): p. 170-185.

11. Antoniou, C., M.G. Kosmadaki, A.J. Stratigos, and A.D. Katsambas, Sunscreens - what's important to know. Journal of the European Academy of Dermatology and Venereology, 2008. 22(9): p. 1110-1119.

12. Sulistyani, S. Review of applications nanoparticles of TiO2 and ZnO in sunscreen. in Proceeding of International Conference On Research, Implementation And Education Of Mathematics And Sciences 2014. 2014. Yogyakarta State University.

13. Serpone, N., D. Dondi, and A. Albini, Inorganic and organic UV filters: Their role and efficacy in sunscreens and suncare products. Inorganica Chimica Acta, 2007. 360(3): p. 794-802.

14. Dodd, A., A. McKinley, T. Tsuzuki, and M. Saunders, Optical and photocatalytic properties of nanoparticulate (TiO2)x(ZnO)1-x powders. Journal of Alloys and Compounds, 2010. 489(2): p. L17-L21.

15. Dao, D.V., M. van den Bremt, Z. Koeller, and T.K. Le, Effect of metal ion doping on the optical properties and the deactivation of photocatalytic activity of $\mathrm{ZnO}$ nanopowder for application in sunscreens. Powder Technology, 2016. 288: p. 366-370.

16. Tsuzuki, T., J. Robinson, and P. McCormick, UV-shielding ceramic nanoparticles synthesised by mechanochemcial processing. Journal of the Australian ceramic society, 2002. 38(1): p. 15-19.

17. González, S., M. Fernández-Lorente, and Y. Gilaberte-Calzada, The latest on skin photoprotection. Clinics in Dermatology, 2008. 26(6): p. 614-626.

18. Becheri, A., M. Dürr, P.L. Nostro, and P. Baglioni, Synthesis and characterization of zinc oxide nanoparticles: application to textiles as UV-absorbers. Journal of Nanoparticle Research, 2008. 10(4): p. 679-689. 
19. Schauder, S. and H. Ippen, Contact and photocontact sensitivity to sunscreens. Contact dermatitis, 1997. 37(5): p. 221-232.

20. Roscher, N.M., M.K. Lindemann, S.B. Kong, C.G. Cho, and P. Jiang, Photodecomposition of several compounds commonly used as sunscreen agents. Journal of Photochemistry and Photobiology A: Chemistry, 1994. 80(1-3): p. 417-421.

21. Serpone, N., A. Salinaro, A.V. Emeline, S. Horikoshi, H. Hidaka, and J. Zhao, An in vitro systematic spectroscopic examination of the photostabilities of a random set of commercial sunscreen lotions and their chemical UVB/UVA active agents. Photochemical \& Photobiological Sciences, 2002. 1(12): p. 970-981.

22. Dransfield, G., Inorganic sunscreens. Radiation protection dosimetry, 2000. 91(1-3): p. 271273.

23. Yousefi, R., A.K. Zak, and F. Jamali-Sheini, The effect of group-I elements on the structural and optical properties of ZnO nanoparticles. Ceramics International, 2013. 39(2): p. 1371-1377.

24. Zholobak, N., V. Ivanov, A. Shcherbakov, A. Shaporev, O. Polezhaeva, A.Y. Baranchikov, N.Y. Spivak, and Y.D. Tretyakov, UV-shielding property, photocatalytic activity and photocytotoxicity of ceria colloid solutions. Journal of Photochemistry and Photobiology B: Biology, 2011. 102(1): p. 32-38.

25. Yabe, S. and T. Sato, Cerium oxide for sunscreen cosmetics. Journal of Solid State Chemistry, 2003. 171(1-2): p. 7-11.

26. Mitchnick, M.A., D. Fairhurst, and S.R. Pinnell, Microfine zinc oxide (Z-cote) as a photostable UVA/UVB sunblock agent. Journal of the American Academy of Dermatology, 1999. 40(1): p. 85-90.

27. Sathishkumar, P., R. Sweena, J.J. Wu, and S. Anandan, Synthesis of CuO-ZnO nanophotocatalyst for visible light assisted degradation of a textile dye in aqueous solution. Chemical Engineering Journal, 2011. 171(1): p. 136-140.

28. Abdollahi, Y., A.H. Abdullah, Z. Zainal, and N.A. Yusof, Photocatalytic degradation of p-Cresol by zinc oxide under UV irradiation. International journal of molecular sciences, 2011. 13(1): p. 302-315.

29. Lee, M.H., U.M. Patil, S.T. Kochuveedu, C.S. Lee, and D.H. Kim, The effect of SiO 2 shell on the suppression of photocatalytic activity of TiO 2 and $\mathrm{ZnO}$ nanoparticles. Bull. Korean Chem. Soc, 2012. 33(11): p. 3767-3771.

30. Tsuzuki, T., R. He, J. Wang, L. Sun, X. Wang, and R. Hocking, Reduction of the photocatalytic activity of ZnO nanoparticles for UV protection applications. International journal of nanotechnology, 2012. 9(10-12): p. 1017-1029.

31. Jiang, J., K. Zhang, X. Chen, F. Zhao, T. Xie, D. Wang, and Y. Lin, Porous Ce-doped ZnO hollow sphere with enhanced photodegradation activity for artificial waste water. Journal of Alloys and Compounds, 2017. 699: p. 907-913.

32. Anandan, S., A. Vinu, K.L.P. Sheeja Lovely, N. Gokulakrishnan, P. Srinivasu, T. Mori, V. Murugesan, V. Sivamurugan, and K. Ariga, Photocatalytic activity of La-doped ZnO for the degradation of monocrotophos in aqueous suspension. Journal of Molecular Catalysis A: Chemical, 2007. 266(1): p. 149-157.

33. Xu, C., L. Cao, G. Su, W. Liu, X. Qu, and Y. Yu, Preparation, characterization and photocatalytic activity of Co-doped ZnO powders. Journal of Alloys and Compounds, 2010. 497(1): p. 373376.

34. Ahmad, M., E. Ahmed, W. Ahmed, A. Elhissi, Z.L. Hong, and N.R. Khalid, Enhancing visible light responsive photocatalytic activity by decorating $\mathrm{Mn}$-doped $\mathrm{ZnO}$ nanoparticles on graphene. Ceramics International, 2014. 40(7): p. 10085-10097.

35. Ahmad, M., E. Ahmed, Y. Zhang, N. Khalid, J. Xu, M. Ullah, and Z. Hong, Preparation of highly efficient Al-doped ZnO photocatalyst by combustion synthesis. Current Applied Physics, 2013. 13(4): p. 697-704. 
36. Benhebal, H., M. Chaib, C. Malengreaux, S.D. Lambert, A. Leonard, M. Crine, and B. Heinrichs, Visible-light photo-activity of alkali metal doped ZnO. Journal of the Taiwan Institute of Chemical Engineers, 2014. 45(1): p. 249-253.

37. Wu, C., L. Shen, Y.-C. Zhang, and Q. Huang, Solvothermal synthesis of Cr-doped ZnO nanowires with visible light-driven photocatalytic activity. Materials Letters, 2011. 65(12): p. 1794-1796.

38. Tsuzuki, T., Z. Smith, A. Parker, R. He, and X. Wang, Photocatalytic activity of manganesedoped $\mathrm{ZnO}$ nanocrystalline powders. Journal of the Australian ceramic society, 2009. 45(1): $\mathrm{p}$. 58-62.

39. He, R., R.K. Hocking, and T. Tsuzuki, Co-doped ZnO nanopowders: location of cobalt and reduction in photocatalytic activity. Materials Chemistry and Physics, 2012. 132(2): p. 10351040.

40. Kaneva, N.V., D.T. Dimitrov, and C.D. Dushkin, Effect of nickel doping on the photocatalytic activity of ZnO thin films under UV and visible light. Applied Surface Science, 2011. 257(18): p. 8113-8120.

41. Gu, P., X. Wang, T. Li, and H. Meng, Investigation of defects in N-doped ZnO powders prepared by a facile solvothermal method and their UV photocatalytic properties. Materials Research Bulletin, 2013. 48(11): p. 4699-4703. 